\title{
Donald Trump, o twitter e as eleições presidenciais dos Estados Unidos de 2016
}

\author{
Donald Trump, twitter and the 2016 presidential elections in \\ USA
}

\section{Andressa Gabrielly de Lacerda Mendes Filipe Almeida do Prado Mendonça}

\section{Resumo}

No século XXI, a intermediação política tem se desenvolvido para além dos meios tradicionais de comunicaçáo, alterando o modo como se entende e mobiliza politicamente a opinião pública. Essa realidade trouxe desafios inéditos para as democracias contemporâneas. Nesse contexto, este artigo busca mapear como Donald Trump usou as redes sociais para comunicar-se diretamente com seus eleitores. A pergunta que orienta a pesquisa é a seguinte: o Twitter de Donald Trump foi um instrumento de criaçáo da agenda da grande imprensa durante as eleiçóes presidenciais dos Estados Unidos de 2016? Partimos da hipótese de que o Twitter de Trump auxiliou na construção das agendas, inclusive das mídias tradicionais, durante a corrida eleitoral. Para tanto, buscamos mapear o Twitter de Trump e sua relação com as redes televisivas estadunidenses. Entendemos que esse elemento é crucial para a compreensão da vitória do Donald Trump na corrida presidencial de 2016.

\section{Palavras-chave}

Mídia; Donald Trump; Twitter; Construção de Agenda; Eleições.

\begin{abstract}
In the XXI century, the media has been developed beyond the traditional means of communication television and radio -, changing the way the public opinion is politically understood and mobilized. This reality brought unprecedented challenges to the contemporary democracies. In this context, this article aims to map how Donald Trump has used social media to communicate directly with his voters. The question that guides the research is: Donald Trump's Twitter was an instrument on the creation of the media agenda during the presidential elections of the United States of 2016? The main hypothesis is that Trump's Twitter assisted in the agenda building, including the traditional media, during the electoral run. To do so, we aim to map Trump's Twitter and its relationship with the American television networks. We understand that this element is crucial to the comprehension of Trump's victory in the electoral run of 2016.
\end{abstract}

\section{Keywords}

Media; Donald Trump; Twitter; Agenda Building; Elections. 


\section{Introdução ${ }^{1}$}

A mídia, seja ela tradicional ou alternativa, está presente na vida política moderna. Diariamente notícias sobre os acontecimentos no mundo são propagadas por inúmeros veículos. Com o advento e desenvolvimento de tecnologias como televisores, celulares e computadores, além da Internet, as informaçôes obtêm grande alcance, moldando a opinião pública e influenciando democracias, com abordagens sobre questóes como economia e política. A mídia tradicional cobre eventos, declarações etc., enquanto atores políticos têm buscado nas redes sociais um mecanismo de comunicação direta com o público.

Esta nova realidade tem gerado inúmeros debates nas mais diferentes áreas do conhecimento. Manuel Castells, na sua obra clássica intitulada $A$ Sociedade em Rede (1992) e, mais tarde, em A galáxia da Internet (2003), já antecipava na Sociologia partes dos dilemas que estão postos no jogo político contemporâneo. $\mathrm{Na}$ comunicação social, destacam-se debates sobre espaço público, a partir da visão de Jürgen Habermas (2003), na era digital, bem como os novos dilemas dos tradicionais e contemporâneos gatekeepers (BRUNS, 2005), bypassing (ENLI, 2017) e o papel das bolhas digitais (PARISER, 2011). Já a Ciência Política e as Relações Internacionais buscam compreender a maneira como as mídias sociais contribuem para a comunicação política (JUNGHERR, 2015), para o ativismo transnacional (VIEIRA, 2016) e para as relações externas entre os países (TROTTIER e FUCHS, 2014).

Donald Trump é um produto desse novo tipo de comunicação política, embora as mídias sociais já tivessem grande relevância em corridas presidenciais anteriores (ENLI, 2017). Desde que anunciou oficialmente sua candidatura à presidência dos Estados Unidos pelo partido republicano, Trump ganhou evidência na imprensa dentro e fora daquele país, geralmente com enfoque negativo. Isso pode ser explicado tanto pelo papel que os Estados Unidos representam no sistema internacional, quanto pela persona de Trump, uma figura caricata. O uso do Twitter por Trump e a constante discordância da mídia tradicional foram marcantes durante as eleições presidenciais dos Estados Unidos em 2016.

Segundo Enli (2017), a literatura de pesquisa sobre mídias sociais e campanhas eleitorais pode ser dividida em três escolas principais. A primeira vertente busca mapear o desenvolvimento histórico de campanhas digitais e o uso de novas

${ }^{1}$ O presente trabalho foi realizado com apoio da Coordenaçáo de Aperfeiçoamento de Pessoal de Nível Superior - Brasil (CAPES) - Código de financiamento 001. 
redes como o Twitter para mobilizar os eleitores (ENLI, 2017; BRUNS e HIGHFIELD, 2016). Segundo Enli (2017), os blogs foram incluídos nas campanhas eleitorais dos EUA a partir de 2004, mas foi a campanha de Obama de 2008 que representou a primeira eleição nas mídias sociais. A segunda vertente analisa o nível de interação com os eleitores nas campanhas de mídia social (ENLI e NAPER, 2016). Ainda segundo Enli (2017), uma descoberta importante nesses estudos é que "[...] politicians are reluctant to engage in dialogue with voters on social media and that campaigns use social media primarily as an arena for political marketing"? (ENLI, 2017, p. 51). A terceira e última linha de pesquisa apresentada por Enli (2017) trata do nível de profissionalização das campanhas (KREISS, 2014).

Diante disso, o presente artigo foca no âmbito interno dos Estados Unidos, mais especificamente no papel da imprensa - tradicional e nova - durante as eleiçôes presidenciais do país em 2016. Busca-se responder à seguinte pergunta: o Twitter de Donald Trump foi um instrumento de criação e controle da agenda da imprensa tradicional durante as eleiçôes presidenciais dos Estados Unidos de 2016? Afirmamos que o Twitter de Trump auxiliou na construção da agenda política da mídia tradicional durante o período em questão, tanto pelo alto número de menções em redes televisivas dentro e fora dos Estados Unidos, quanto pelo modo como ele se expressava publicamente, sem filtros. Em outras palavras, os dados que mobilizamos nos permitem afirmar que a estratégia de Donald Trump nas redes sociais serviu para controlar a sua comunicação política, pautando inclusive veículos tradicionais de imprensa.

Para tanto, o artigo será composto de três seçôes e considerações a título de conclusão. A primeira sobre o Twitter e a construção da agenda nos Estados Unidos, de um modo geral; a segunda a respeito dos conceitos de opinião pública, democracia e da corrida presidencial nos Estados Unidos; a terceira sobre o Twitter e a construção da agenda nas eleiçôes de 2016 nos Estados Unidos. Por fim, considerações a título de conclusão serão apresentadas.

\section{O Twitter e a construção da agenda nos Estados Unidos}

Desde o último século, o rádio e a televisão foram os principais meios tecnológicos de informação existentes. Com o advento da Internet, computador e celulares móveis, as notícias passaram a ser difundidas por outros meios. Esse

\footnotetext{
2 Tradução nossa: políticos estão relutantes em se engajar em um diálogo com outros votantes nas redes sociais, e campanhas usam as redes sociais principalmente como marketing político.
} 
processo, denominado por Nye (2002) de Revolução da Informação (comumente conhecida como Terceira Revolução Industrial), refere-se ao desenvolvimento da comunicação, informação e tecnologia, em que o poder passa a ser difundido para além do âmbito estatal, com o empoderamento de atores não-estatais para realizar um papel maior no mundo político.

A partir da segunda década do século XXI, as redes sociais - Twitter, Facebook, Instagram, Whatsapp, Youtube, blogs e outros -, têm sido fontes de informação e de disseminação de notícias. Elas não excluem, no entanto, a mídia tradicional - revistas, jornais escritos ${ }^{3}$ ou transmitidos pela televisão ou rádio. Pelo contrário, complementam o que é transmitido por estas últimas. Segundo Ledford (2012, p. 9), "[...] this need for complementarity is emphasized in crises when publics will more frequently share information sources from an online newspaper column than an organizational blog post or Twitter message"4.

Apesar disso, entende-se que as redes sociais têm sido importantes fontes de informação. É o que defendem alguns políticos, como Donald Trump (presidente dos EUA) ou Jair Bolsonaro (presidente do Brasil), por exemplo, que acreditam que as redes sociais são a melhor forma de difundir notícias sobre si mesmos ou assuntos relacionados, por serem um meio direto entre o comunicador e o público. Por meio das mídias sociais, não há o intermédio daqueles que trabalham com a mídia tradicional, evitando o que ambos chamam de fake news ${ }^{5}$. A Internet também permite a criação de espaços que compartilham propagandas, propostas e planos de governo diretamente dos candidatos para o seu público alvo, como é o site oficial de Donald Trump, o Trump Pence (MAZA, 2018; TRUMP PENCE, 2019).

Uma das mídias sociais que mais foi usada como fonte de compartilhamento de informação durante as eleições presidenciais dos Estados Unidos de 2016 foi o Twitter. Lançado em 2006, o Twitter permite que usuários compartilhem textos denominados de tweets - de até 280 caracteres $^{6}$, além de ser possível anexar fotos,

\footnotetext{
${ }^{3}$ Ressalta-se que a maior parte dos jornais escritos tem um editorial para sites informativos na Internet, que podem, ou náo ser assinados pelas pessoas. Eles seráo considerados parte da mídia tradicional neste artigo.

${ }^{4}$ Tradução nossa: Essa necessidade por complementaridade é enfatizada em crises, quando o público irá compartilhar fontes de informaçóes de jornais mais frequentemente do que de um blog organizacional ou mensagem do Twitter.

5 Tradução nossa: notícias falsas.

${ }^{6}$ Ressalta-se aqui que durante as eleiçóes de 2016, o site permitia tweets de até 140 caracteres apenas. A mudança ocorreu no dia 07/11/2017 (TWITTER..., 2017).
} 
vídeos ou áudios a eles. Nessa rede, os usuários seguem contas que lhe interessam e podem, do mesmo modo, ser seguidos. A interação, por sua vez, se dá por meio de respostas públicas (replies) a determinado tweet ou por mensagem direta; nesse último caso, apenas as duas pessoas se comunicando têm acesso às mensagens (ARTHUR, 2010).

Além disso, os usuários podem fazer retweets (mais conhecidos como $R T$ ), que é o mesmo que publicar na sua página algo escrito por outra pessoa, além de curtir tweets feitos por outros. Em ambos os casos, aqueles que seguem a pessoa que curtiu ou deu retweet no tweet do outro poderão ver o tweet na sua própria timeline . Outra característica do site é o uso frequente de hashtags pelos usuários. As hashtags seriam palavras-chave precedidas da cerquilha "\#” e que indicam o tema que está sendo compartilhado. Um exemplo é a hashtag \#makeamericagreatagain usada na campanha de Trump. Elas são, por fim, ferramentas para medir a relevância e ocorrência de um determinado assunto na plataforma (DRUBSCKY, 2018; TRUMP, 2019).

Em relação ao caso de interesse para este artigo, Donald Trump possui duas contas no site: uma pessoal, cujo usuário é @realDonaldTrump - com, até a construção deste artigo (agosto de 2019), 62,5 milhões de seguidores - e outra oficial do cargo de presidente dos Estados Unidos, a @POTUS - com, também até julho de 2019, 26,4 milhões de seguidores (TRUMP, 2019). Márquez-Domínguez, LópezLópez e Arias (2017), ao comparar os conteúdos e discurso das duas contas do Twitter de Trump (a pessoal, @realDonaldTrump, e a institucional, @POTUS), por meio do cruzamento de análise de dados obtidos entre os dias 9 de março e 5 de abril, concluem que ambas as contas, em geral, lidam com palavras e hashtags frequentemente relacionadas com a presunçáo e o domínio do excepcionalismo estadunidense, de acordo com o moto eleitoral de Trump: Make America Great $\operatorname{Again}^{8}$. De um ponto de vista temático, há uma agenda muito semelhante entre as duas contas do Twitter analisadas: referências a políticas públicas e situações genéricas do cenário político. No entanto, a conta pessoal de Trump é mais utilizada para reivindicar sua figura pessoal e atacar seus adversários e, portanto, é a conta a ser analisada aqui.

\footnotetext{
${ }^{7}$ Essa função é restrita, no entanto, para aqueles que possuem contas privadas, em que ninguém além de quem as segue pode ver o que ela posta e, por conseguinte, fazer retweets ou curtir seus tweets. Para segui-las é preciso pedir permissão.

8 Tradução nossa: Faça a América grande novamente.
} 
A relação entre a mídia tradicional e as novas mídias é abordada pelas teorias de configuração de agenda (agenda setting) e construção de agenda (agenda building). Segundo Lee e Xu (2018), a primeira deriva dos estudos de McCombs e Shaw's (1972 apud LEE e XU, 2018) e consiste na transferência da agenda da mídia para a agenda pública, em que a mídia diz para as pessoas o que pensar ao transmitir questóes consideradas importantes por ela mesma. A segunda, por sua vez, é uma extensão da primeira, e consiste na ideia de que a agenda da mídia é engendrada, ou seja, outros atores, como políticos, organizações, grupos ativistas, entre outros, influenciam na construção da agenda midiática por meio de informaçóes conferências de imprensa ou vazamento de vídeos. Assim, os outros atores influenciam e até moldam a agenda midiática e, consequentemente, a opinião pública.

Segundo Conway-Silva et al. (2017), em acordo com Lee e Xu (2018), as redes sociais impactam na construção da agenda da mídia tradicional e têm se tornado importantes. Nas eleiçôes de 2016, por exemplo, 62\% dos estadunidenses receberam notícias diretamente das redes sociais, sendo o Facebook o mais popular, e o Twitter - com cerca de $24 \%$ daqueles que navegam na Internet - usado para obter informaçôes sobre notícias e eventos, inclusive com foco em política. É nesse sentido, portanto, que os trabalhos dos autores mencionados buscam entender como o Twitter pode ser um meio de construção de agenda midiática.

Conway-Silva et al. (2017) procuram testar a dinâmica de construção de agenda durante as eleições de 2016, comparando-a com resultados de estudos prévios e documentando o desenvolvimento do papel do Twitter no ambiente de comunicação político. O estudo mostra três potenciais resultados da construção e configuração de agenda no Twitter: (1) domínio top-down de notícias midiáticas (que seria a mídia tradicional prever a agenda do Twitter); (2) relacionamentos recíprocos, ou seja, tanto a mídia tradicional prever a agenda do Twitter quanto o Twitter prever agenda antes da mídia tradicional; e (3) mensagem bottom-up, em que as redes sociais diminuem ou aumentam o poder de agenda-setting da mídia tradicional (CONWAY-SILVA et al., 2017).

Ainda segundo Conway-Silva et al. (2017), a hipótese do relacionamento recíproco, de que ambas as mídias - tradicional e nova - constroem a agenda é comprovada como a que acontece com mais frequência. Assim, por meio de uma análise qualitativa e quantitativa com dados obtidos de jornais estadunidenses (The Wall Street Journal, The New York Times, USA Today, The Los Angeles Times e 
The Washington Post) e de Twitters dos candidatos à presidência entre $1^{\circ}$ de janeiro e 7 de julho, os autores chegam à conclusão de que a mídia tradicional teve mais capacidade de predição da agenda que o Twitter.

Conway-Silva et al. (2017) não avaliam, no entanto, o tom empregado pelos candidatos na mídia, ou seja, se os tweets ou a abordagem pela mídia tradicional foram positivos ou negativos. Diferentemente deles, Lee e Xu (2018), na busca por contribuir para a literatura de configuração da agenda e de campanhas políticas, examinam as agendas de candidatos presidenciais - Donald Trump e Hillary Clinton - no Twitter e as reaçóes dos usuários durante o período eleitoral de 2016. Uma das variáveis de análise escolhida pelos autores é o tweet de ataque (attack tweet), que consiste em postagens agressivas de investida contra outro candidato. Segundo os autores, "[...] with attack ads, candidates aim to convert votes by drawing attention to an issue they have credibility in handling but upon which the opponent is weak ${ }^{\text {" }}$ (LEE e XU, 2018, p. 4).

De fato, as eleições presidenciais de 2016 foram marcadas por discursos de ódio e insultos de um candidato a outro. Essa polarização, inclusive entre os partidos republicano e democrata, mantém a comunicação política negativa. Isso levou ao seguinte problema: quão comuns são os tweets de ataque a candidatos durante a campanha? Os tweets de ataque recebem mais retweets e curtidas? Para Lee e $\mathrm{Xu}$ (2018), a resposta e conclusão a essas perguntas, após a análise, foi a de que o Twitter foi mais frequentemente usado por ambos os candidatos para atacar o outro - ou mesmo atores externos - do que para se autopromover. Assim, Trump conseguiu promover sua agenda mais do que Clinton ao obter maior engajamento dos seguidores, os quais apoiam majoritariamente tweets de ataque, que "[...] can also have agenda building effects because candidates' negative messages tend to be reported by the news media more than positive messages"10 (LEE e XU, 2018, p. 11).

\section{Opinião pública, Democracia e corrida presidencial nos Estados Unidos}

Outras duas questóes de suma importância nesse debate sobre o uso do Twitter como meio de propagação de informação em contraponto à mídia

\footnotetext{
9 Tradução nossa: com anúncios de ataques, os candidatos buscam converter votos ao chamar a atenção para uma questão que eles têm credibilidade para lidar, mas para a qual o oponente é fraco.

10 Tradução nossa: pode, também, haver efeitos de construção de agenda porque as mensagens negativas dos candidatos tendem a ser reportadas pelos meios de comunicação mais do que as mensagens positivas.
} 
tradicional, são as variáveis opinião pública e democracia. A primeira está intimamente ligada à mídia, por ser também através dela que o público se informa e se posiciona politicamente. A literatura aponta que, antes, essa relação dependia exclusivamente da mídia tradicional. Não obstante, com a popularização das redes sociais, a forma como se constrói as agendas e, por conseguinte, a opinião pública sofreu profundas alterações (McCOMBS, 2018). Magnotta e Grinberg (2018), por exemplo, abordam essa questão relacionada às eleições de 2016 ao empregar o conceito da espiral do silêncio, advindo da psicologia social.

Com o objetivo de analisar a vitória de Trump à luz da relação entre a mídia e a opinião pública, Magnotta e Grinberg (2018) entendem que, com a contribuição da mídia, a narrativa contra Trump tornou-se dominante no país, o que teria desencorajado parte do eleitorado a manifestar publicamente seu apoio ao candidato, ainda que tivessem a intenção efetiva de direcionar seu voto a ele. Isso ajuda a explicar o motivo pelo qual, apesar do que era retratado pelas pesquisas de opinião, a vitória de Trump aconteceu. Essa hipótese inicial é comprovada ao se aplicar a teoria da espiral do silêncio, que consiste na ideia de que as pessoas identificam opinióes dominantes e, pelo medo do isolamento social, evitam expressar opinióes que possam levar a críticas ou sanções (MAGNOTTA e GRINBERG, 2018).

A influência da mídia sobre a opinião pública centraliza a narrativa dominante e exerce um meio de controle social - a configuração da agenda (McCOMBS, 2018). Ela guia o consumidor com o que passa a ser interpretado como mais importante ou como leitura predominante de determinada realidade. As redes sociais, nesse caso, seriam âncoras ideológicas que pautavam a campanha de Trump devido à dinâmica entre ele e a mídia. Segundo os autores, isso "[...] criou uma grande bolha que permeou o eleitorado e que, de alguma forma, poderia ser apontado um dos indicativos dos custos sociais de se contrapor ao mainstream" (MAGNOTTA e GRINBERG, 2018, p. 399).

No que tange à variável de democracia, Van Aelst et al. (2017) apresentam que a comunicação em diversos sistemas políticos liberais e democráticos tem mudado com o aumento da mídia digital e móvel. $\mathrm{O}$ ambiente informacional político tem sido pautado por bolhas de filtro em forma de algoritmo, e nele as pessoas só consomem um conteúdo específico, visto que tal filtro transforma de maneira invisível a experiência de mundo das pessoas. Além disso, Van Aelst et al. (2017) entendem que o jornalismo político está se tornando mais superficial e sensacionalista, em vez de informativo e investigativo. Por outro lado, as mudanças 
tecnológicas midiáticas têm estendido a escolha da liberdade e aumentado a criatividade, assim como as oportunidades de cidadáos e sociedade civil participarem da esfera pública. Essa contradição pode ser percebida ao opor a mídia tradicional das grandes corporaçóes com a mídia independente e alternativa, muitas vezes com sede na Internet.

A democracia, a partir disso, é entendida não só como instituições, mas como um processo que garante a todos os cidadãos oportunidades de participar de políticas, expressar opinióes e influenciar processos de tomada de decisão. Ela requer não só direitos formais, mas também direitos informais, como entendimento, participação e inclusão. Assim, o ambiente midiático se apresentaria como um desafio à democracia devido ao aumento da fragmentação, polarização, desigualdades e relativismo crescentes no conhecimento político (VAN AELST et al., 2017).

Esse cenário é perceptível no caso dos Estados Unidos, quando se entende que as eleiçôes de 2016 foram uma das mais disputadas em anos, tanto que o resultado final foi polêmico, uma vez que Donald Trump foi eleito presidente dos Estados Unidos com maioria no Colégio Eleitoral (306 a 232) contra Hillary Clinton, mas com minoria no número direto de eleitores (45,9\% para ele a $49 \%$ para ela). Ademais, o entrave entre ambos, não só noticiado pela mídia tradicional, mas também difundido pelo Twitter - diretamente das contas dos dois candidatos reforça essa polarização e ameaça a democracia do país (PRESIDENTIAL..., 2017).

Levitsky e Ziblatt (2018) também afirmam que a polarização extrema pode destruir democracias. Ao buscar entender como as democracias morrem, os autores apresentam como a democracia estadunidense pode estar ameaçada não só pela polarização, mas também, e principalmente, pela figura de Donald Trump, que seria uma figura de caráter ditatorial, o que poderia vir a ameaçar a democracia dos Estados Unidos.

Para corroborar a hipótese, os autores apresentam, com base no trabalho de Juan Linz, um cientista político alemão, quatro sinais de alerta para reconhecer um autoritário: “[...] quando políticos: 1) rejeitam, em palavras ou ações, as regras democráticas do jogo; 2) negam a legitimidade de oponentes; 3) toleram e encorajam a violência; e 4) dão indicações de disposição para restringir liberdades civis de oponentes, inclusive a mídia" (LEVITSKY e ZIBLATT, 2018, p. 23). Acrescentam, ainda, que candidatos outsiders populistas, ou seja, pessoas que não fazem parte do sistema, tendem a se encaixar no perfil.

Em suma, a mídia - tanto a tradicional quanto a nova - está diretamente relacionada com opinião pública e democracia. Ela tem o poder de moldar a opinião 
pública e é tanto um indicador da democracia de um país - por ter liberdade de expressáo, por exemplo - quanto uma ameaça a essa democracia, por propor pautas que fomentem a polarização, desigualdade e agressividade entre as pessoas. A nova mídia, em especial o Twitter, tem tido grande papel na construção da agenda midiática.

A partir disso, a próxima seção busca explicar se houve ou não criação da agenda empregada pela mídia tradicional pelos tweets de Trump.

\section{O Twitter e a construção da agenda nas eleições de 2016 nos Estados Unidos}

O Twitter foi uma ferramenta fundamental para Donald Trump durante as eleições de 2016. $\mathrm{Na}$ análise que segue incluiremos os tweets, replies e retweets manuais - com exceção de retweets normais ${ }^{11}$ - de Trump desde o dia $1^{\circ}$ de fevereiro de 2016 - data da convenção de Iowa - até o dia 20 de janeiro de 2017 - data em que Trump foi nomeado oficialmente presidente dos Estados Unidos. A escolha desse intervalo se deu devido ao fato de ele cobrir a maior parte do período eleitoral, desde o início efetivo das primárias e caucus ${ }^{12}$, com a Conferência de Iowa, até a posse ${ }^{13}$ (DELREAL, 2015; KIMBALL, 2016).

Para entender se o Twitter de Trump foi instrumento na construção da agenda da mídia tradicional durante as eleições dos EUA de 2016, faremos uma exposição e posterior análise das principais palavras usadas por Trump em seu Twitter e de seus tweets com maior engajamento - por número de curtidas e retweets -, de modo a classificar quais assuntos são mais frequentemente usados por ele. A partir disso, mostraremos os dados sobre a cobertura da mídia tradicional nas eleições de 2016 e sobre Donald Trump. Os tweets foram obtidos através do site Trump Twitter Archive, onde é feita uma compilação instantânea de todos os tweets de Trump. Durante o período desta análise, Trump escreveu aproximadamente 3.700 tweets, retweets manuais e replies inclusos. A partir de todos os tweets do período, foi feito um processamento no site Voyant Tools para descobrir quais as palavras mais

\footnotetext{
${ }^{11}$ Os retweets normais não estão inclusos na contagem, pois eles não são escritos por Trump, ainda que ele os tenha corroborado.

${ }^{12}$ Convenção partidária.

${ }^{13}$ Trump anunciou sua candidatura à presidência oficialmente dia 16 de junho de 2015. No entanto, foi a partir do dia $1^{\circ}$ de fevereiro de 2016 que a campanha oficialmente começou, com a disputa das primárias e caucus, ou seja, uma disputa interna dos partidos e seus eleitores, para saber quem será o indicado a concorrer à presidência (DELREAL, 2015; KIMBALL, 2016).
} 
frequentes nos tweets de Trump. Foram excluídas da contagem as seguintes categorias de palavras: verbos (com exceçáo de vote ${ }^{14}$ ), pronomes, advérbios, conjunçôes, preposiçôes, números, símbolos, artigos, adjetivos (com exceção de crooked ${ }^{15}$ ) e os substantivos thanks, iphone, android, time, supporters, morning, Twitter e night ${ }^{16}$.

As palavras make ${ }^{17}$ e great ${ }^{18}$, apesar de aparecerem com muita frequência, foram excluídas por normalmente serem associadas à expressão Make America Great Again, que já foi contabilizada, e porque podem estar inseridas em outro contexto, que não pode ser inferido somente com base em seus significados. $\mathrm{O}$ verbo vote foi mantido por náo depender de complemento ou contexto para que seu significado seja entendido - no caso, vote seria um chamado para que seus seguidores votassem nele. A palavra crooked foi mantida, pois, na maioria das vezes em que foi empregada, o foi como um adjetivo ou vocativo à Hillary Clinton. As demais foram excluídas, pois não são dotadas de significado independente, ou seja, sem contexto não é possível saber a que se referem.

Com base nisso, as 25 palavras que mais aparecem nos tweets de Trump são: Hillary (427), people (265), America (264), Clinton (262), crooked (230), makeamericagreatagain (222), trump2016 (216), vote (152), president (139), Cruz (136), CNN (117), media (115), country (115), jobs (100), debate (96), Ted (95), Ohio (92), Foxnews (86), Florida (86), campaign (83), americafirst (81), MAGA (81), american (81), Obama (79) e Carolina (78). Elas estão ilustradas na Figura 1.

\footnotetext{
${ }^{14}$ Tradução nossa: votar.

15 Tradução nossa: desonesto (a).

${ }^{16}$ Tradução nossa: obrigado, iphone, android, tempo, apoiadores, manhã, Twitter e noite.

${ }^{17}$ Tradução nossa: fazer.

18 Tradução nossa: grande.
} 
Figura 1 - Top 25 palavras mais mencionadas por Trump em seu Twitter

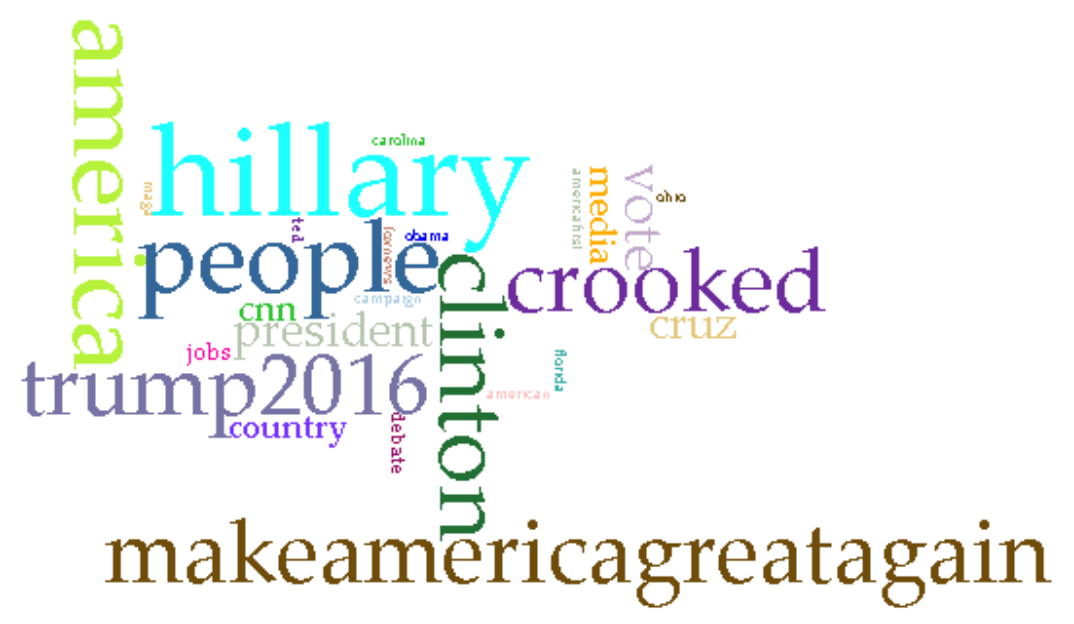

Fonte: Elaboração própria na plataforma Voyant Tools com base em Trump Twitter Archive (BROWN, 2017).

As palavras apresentadas auxiliam na contextualização do que é majoritariamente falado por Trump em seu Twitter. Infere-se que seu foco, durante o período delimitado, foi de mencionar a sua concorrente Hillary Clinton, citar a mídia - Foxnews, CNN - e fazer campanha para si mesmo. Baseado no trabalho de Lee e $\mathrm{Xu}$ (2018), sabe-se que grande parte dos tweets de Trump foram de ataque à Hillary Clinton. A aparição da palavra crooked indica isso, uma vez que foi comumente usada para se referir à Clinton, inclusive com o uso da hashtag \#CrookedHillary. As menções à mídia, por sua vez, podem ser entendidas como parte da relação conflituosa que Trump desenvolveu com a própria mídia. Já o uso das hashtags \#Makeamericagreatagain, \#MAGA (abreviação da anterior) e \#AmericaFirst ${ }^{19}$ e as demais palavras é referente à campanha eleitoral da época, com Trump buscando obter votos com base no engajamento com seus seguidores do Twitter.

Entre todos os tweets do período, os cinco com mais retweets e curtidas podem ser observados nos Quadros 1 e 2.

\footnotetext{
${ }^{19}$ Tradução nossa: América em primeiro lugar.
} 
96 | Andressa Mendes e Filipe Mendonça

Quadro 1 - Top 5 tweets com mais retweets de Donald Trump

\begin{tabular}{|c|c|c|c|}
\hline POSIÇÃO & CONTEÚDO & DATA & $\begin{array}{l}\text { NÚMERO } \\
\text { DE } \\
\text { RETWEETS }\end{array}$ \\
\hline 1 & TODAY WE MAKE AMERICA GREAT AGAIN! $!^{20}$ & $\begin{array}{c}11-08-2016 \\
11: 43: 14\end{array}$ & 344806 \\
\hline 2 & $\begin{array}{l}\text { Such a beautiful and important evening! The } \\
\text { forgotten man and woman will never be forgotten } \\
\text { again. We will all come together as never before }\end{array}$ & $\begin{array}{c}11-09-2016 \\
11: 36: 58\end{array}$ & 220796 \\
\hline 3 & $\begin{array}{l}\text { How long did it take your staff of } 823 \text { people to } \\
\text { think that up--and where are your } 33000 \text { emails that } \\
\text { you deleted? https://t.co/gECLNtQizQ }\end{array}$ & $\begin{array}{c}06-09-2016 \\
20: 40: 32\end{array}$ & 168765 \\
\hline 4 & $\begin{array}{c}\text { The media is spending more time doing a forensic } \\
\text { analysis of Melania's speech than the FBI spent on } \\
\text { Hillary's emails. }\end{array}$ & $\begin{array}{c}07-20-2016 \\
15: 36: 06\end{array}$ & 120661 \\
\hline 5 & Fidel Castro is dead ${ }^{24 !}$ & $\begin{array}{c}11-26-2016 \\
13: 08: 11\end{array}$ & 99483 \\
\hline
\end{tabular}

Fonte: Elaboração própria com base em Trump Twitter Archive (BROWN, 2017).

${ }^{20}$ Tradução nossa: Hoje fazemos a América grandiosa novamente (TRUMP, 2016c).

${ }^{21}$ Tradução nossa: Uma noite tão linda e importante! O homem e a mulher esquecidos nunca mais serão esquecidos. Nós todos vamos juntos como nunca antes (TRUMP, 2016d).

${ }^{22}$ Quanto tempo sua equipe de 823 pessoas demorou para pensar nisso? E onde estão seus 33.000 emails que você deletou? (TRUMP, 2016a).

23 Tradução nossa: A mídia está se debruçando mais em fazer uma análise forense do discurso da Melania do que o FBI se debruçou nos e-mails de Hillary (TRUMP, 2016b).

${ }^{24}$ Tradução nossa: Fidel Castro está morto! (TRUMP, 2016e). 
Quadro 2 - Top 5 tweets mais curtidos de Trump

\begin{tabular}{|c|c|c|c|}
\hline POSIÇÃO & CONTEÚDO & DATA & $\begin{array}{c}\text { NÚMERO DE } \\
\text { CURTIDAS }\end{array}$ \\
\hline 1 & $\begin{array}{c}\text { Such a beautiful and important evening! The } \\
\text { forgotten man and woman will never be forgotten } \\
\text { again. We will all come together as never before }\end{array}$ & $\begin{array}{c}11-09-2016 \\
11: 36: 58\end{array}$ & 633253 \\
\hline 2 & TODAY WE MAKE AMERICA GREAT AGAIN! & $11-08-2016$ & 573283 \\
& How long did it take your staff of 823 people to & $06-09-2016$ & 297281 \\
\hline 3 & you deleted? https://t.co/gECLNtQizQ & $20: 40: 32$ & \\
\hline 4 & $\begin{array}{c}\text { It all begins today! I will see you at 11:00 A.M. for } \\
\text { the swearing-in. THE MOVEMENT }\end{array}$ & $\begin{array}{c}01-20-2017 \\
12: 31: 53\end{array}$ & 268372 \\
& CONTINUES - THE WORK BEGINS? & & \\
\hline \multirow{2}{*}{5} & The media is spending more time doing a forensic & $07-20-2016$ & 249249 \\
& analysis of Melania's speech than the FBI spent on & $15: 36: 06$ & \\
& Hillary's emails. & & \\
\hline
\end{tabular}

Fonte: Elaboração própria com base em Trump Twitter Archive (BROWN, 2017).

Percebe-se que houve pouca variação entre os tweets com mais retweets e curtidas. A maioria só muda de uma posição no ranking para outra. Os tweets "TODAY WE MAKE AMERICA GREAT AGAIN!", do dia 08 de novembro de 2016 (do inglês 11-08-16), e "Such a beautiful and important evening! The forgotten man and woman will never be forgotten again. We will all come together as never before", do dia 09 de novembro de 2016 (do inglês 11-09-16), são referentes à campanha eleitoral de Trump e relacionados às eleições que aconteceram no dia 08 de novembro, que resultaram na vitória de Trump (McCARTHY e PHIPPS, 2016).

O tweet "How long did it take your staff of 823 people to think that up--and where are your 33000 emails that you deleted? https://t.co/gECLNtQizQ”, do dia 9 de junho de 2016, foi uma resposta a um tweet de Hillary Clinton, que dizia "delete your account", em resposta à outro tweet de Trump sobre o endosso de Obama à campanha de Hillary. No $3^{\circ}$ tweet com mais retweets e curtidas de Trump, o presidente pergunta sobre e-mails deletados de Hillary, uma referência às investigações do FBI sobre os e-mails enviados por Hillary enquanto ela era Secretária do Estado durante o governo Obama (IANDOLI, 2016).

25 Tradução nossa: Tudo começa hoje! Verei vocês às 11 horas da manhá para o juramento. O movimento continua. O trabalho começa (TRUMP, 2017). 
O tweet "The media is spending more time doing a forensic analysis of Melania's speech than the FBI spent on Hillary's emails", referente às investigaçóes sobre os e-mails de Hillary, é uma crítica à mídia tradicional, a qual, segundo Trump, se deteve mais no discurso feito por Melania na Convenção Nacional Republicana do que deveria. A polêmica em torno do discurso dela é que este teria sido plagiado de outro discurso de Michelle Obama de 2008 (MELANIA..., 2016).

O tweet "Fidel Castro is dead" refere-se à morte de Fidel Castro, que aconteceu no dia 25 de novembro de 2016. Esse é um caso emblemático que demonstra bem a capacidade adquirida por Trump de pautar a imprensa tradicional. Após esse tweet, a CNN deu a manchete "Donald Trump: Fidel Castro is dead!" (SCOTT, 2016), o Washington Post publicou a manchete "Fidel Castro is dead, but Donald Trump could give Cuba's dictatorship new life” (ROBINSON, 2016), e a NBC, “'Fidel Castro Is Dead!' Trump Tweets, Attacks Legacy as a 'Brutal Dictator'” (CHUCK, 2016), entre centenas de outras manchetes. Por fim, o tweet "It all begins today! I will see you at 11:00 A.M. for the swearing-in. THE MOVEMENT CONTINUES - THE WORK BEGINS!” refere-se à posse de Trump como presidente dos Estados Unidos (FIDEL..., 2016).

Esses tweets demonstram que o Twitter de Trump foi um instrumento de propaganda política eleitoral e um espaço de insultos, críticas e até discussões, especialmente contra a principal adversária de Trump, Hillary Clinton. A combinação desses fatores contribuiu para que a mídia tradicional mantivesse a figura de Trump em foco durante suas transmissões.

Uma análise feita pelo Projeto GDELT Project (2019) usando dados da Internet Archive's Television News Archive, criou um banco de dados com registro em gráficos interativos de quantas vezes cada presidente dos Estados Unidos foi mencionado em cada uma das maiores redes de televisão monitoradas pelo arquivo. Eles são baseados na varredura dos registros de legenda oculta de cada transmissão, portanto estão sujeitos a certo grau de erro. $\mathrm{O}$ arquivo monitora uma seleção de redes nacionais televisivas (Aljazeera America, Bloomberg, CNBC, CNN, Comedy Central, FOX Business, FOX News, LinkTV, MSNBC) e um conjunto crescente de afiliados em todo o país. A escolha por essas redes se deu pelo fato de elas mencionarem os candidatos políticos em um número significativo de vezes. Ressaltase que todos os noticiários em cada estação são monitorados, com a única exceção do Comedy Central, no qual apenas o The Daily Show, com Jon Stewart, The Nightly Show With Larry Wilmore e At Midnight With Chris Hardwick são monitorados, devido ao foco em eventos atuais (GDELT PROJECT, 2019). 
Assim, o número de menções dos candidatos à presidência dos Estados Unidos pode ser visualizado na Figura 2 - Mençôes Televisivas dos Candidatos, Figura 3 - Número das mençóes televisivas por Rede, Figura 4 - Porcentagem das Mençóes dos Democratas por Candidato e Figura 5 - Porcentagem das Menções dos Republicanos por Candidato. A primeira mostra o número de mençôes que as redes televisivas fizeram dos candidatos à presidência durante os anos 2015, 2016 e 2017. Para a seguinte análise, serão contabilizadas as mençôes entre $1^{\circ}$ de fevereiro de 2016 e 20 de janeiro de 2017. Evidencia-se, assim, que Donald Trump foi extremamente mais mencionado que os demais candidatos. Hillary Clinton é a segunda colocada, e sua maior aproximação das mençôes de Trump ocorreu no período em que ambos disputaram quase que diretamente as eleições ${ }^{26}$ - pós-primárias e caucus, em julho de 2016.

Figura 2-Mençóes Televisivas dos Candidatos

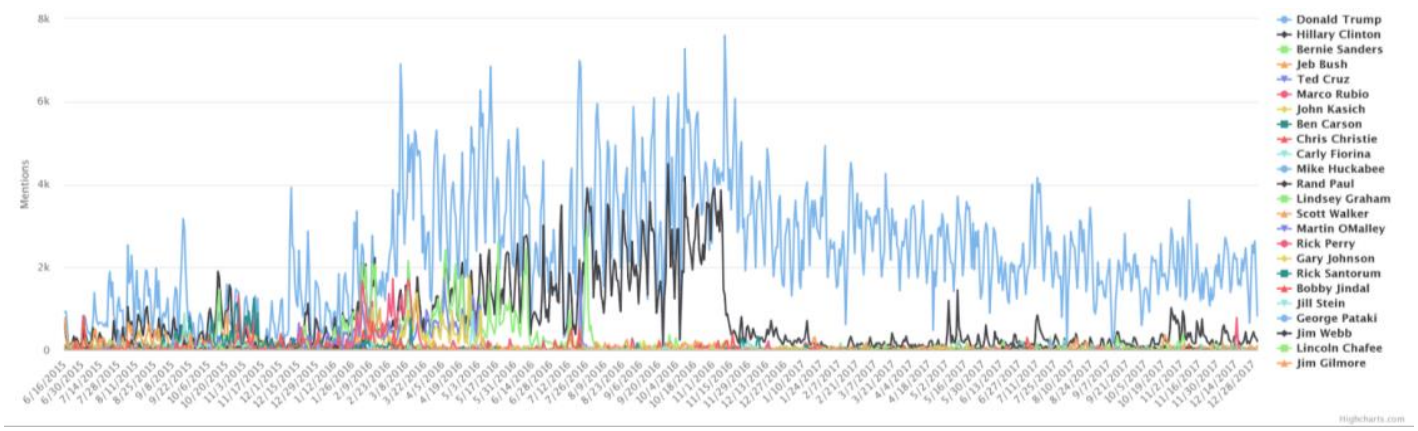

Fonte: GDELT Project (2019).

\footnotetext{
${ }^{26}$ Ressalta-se aqui que havia outros candidatos na disputa, de partidos menores que o Republicano e Democrata, como Darrell Castle, do Partido da Constituição, Jill Stein, do Partido Verde, e Gary Johnson, do Partido Libertário (US POLITICAL..., 2016).
} 
Figura 3 - Número das mençóes televisivas por Rede

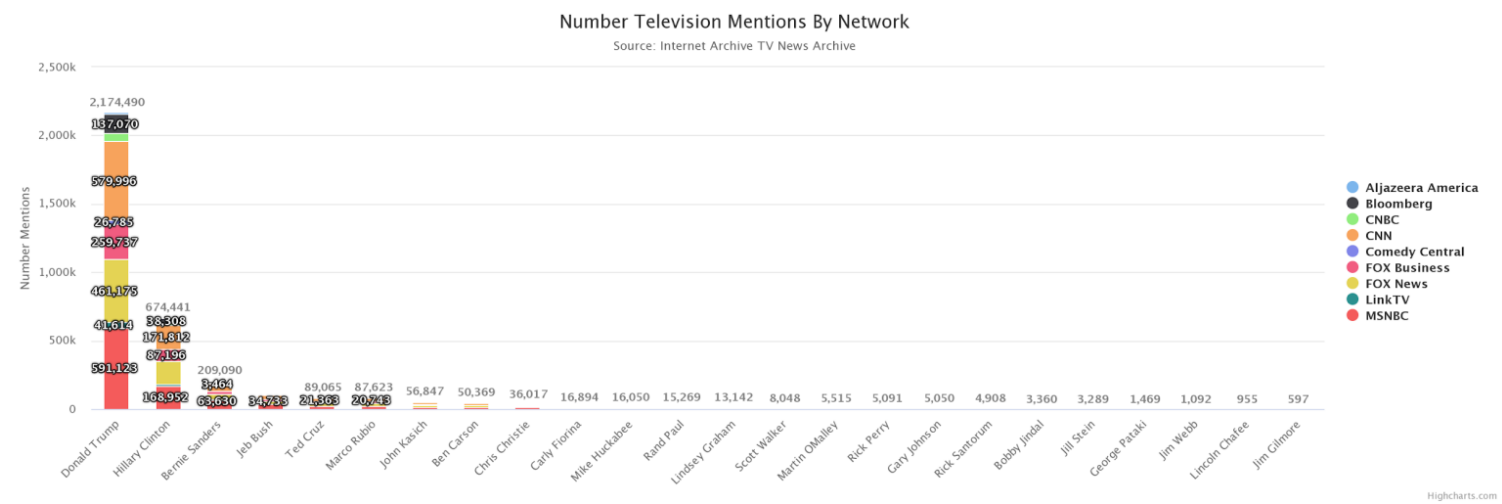

Fonte: GDELT Project (2019).

Figura 4 - Porcentagem das Mençóes dos Democratas por Candidato

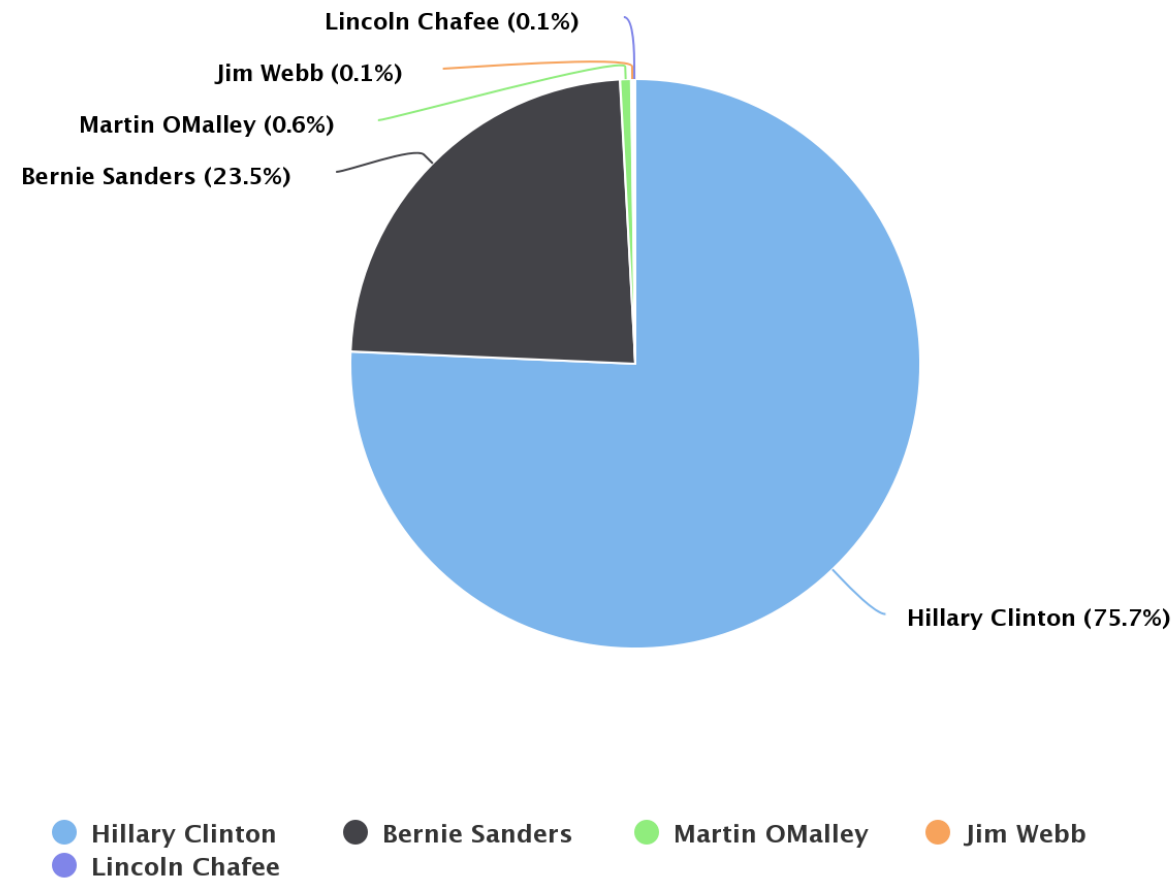

Fonte: GDELT Project (2019). 
Figura 5 - Porcentagem das Mençóes dos Republicanos por Candidato

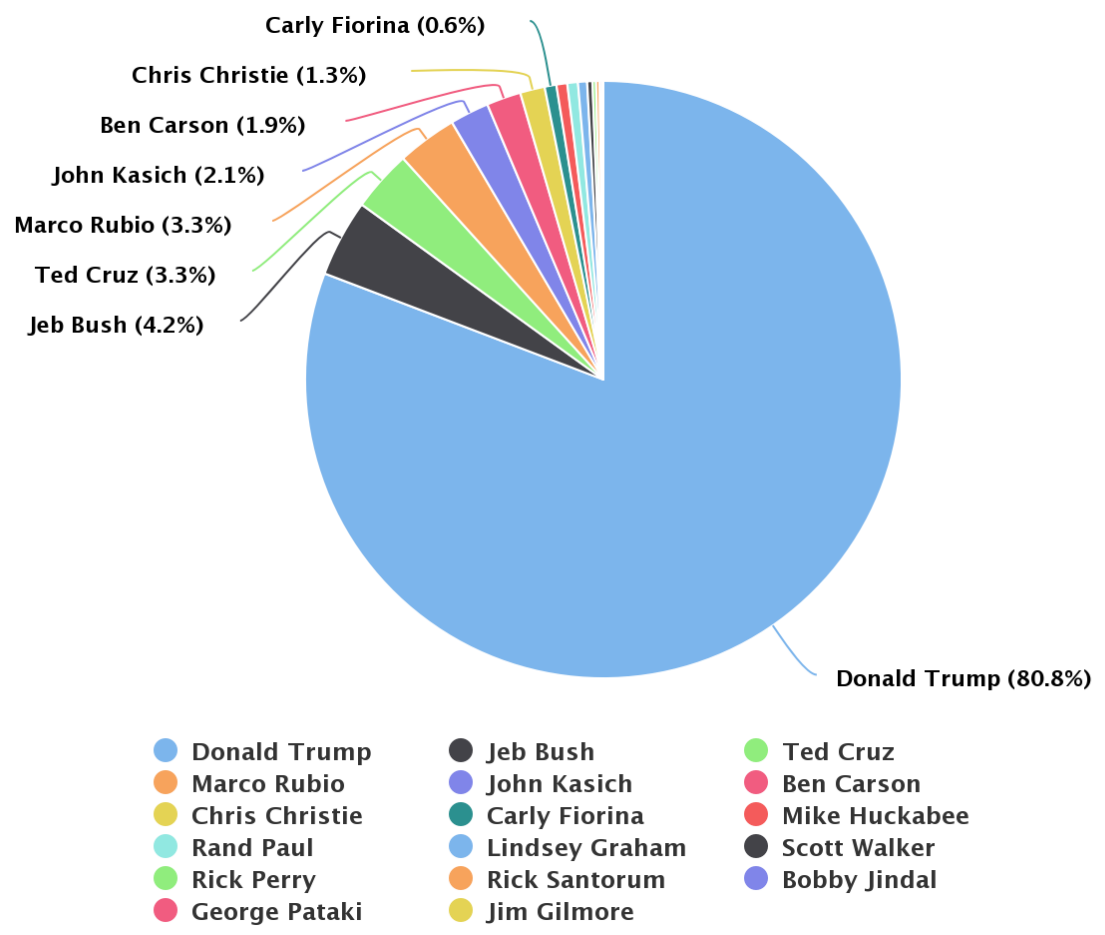

Fonte: GDELT Project (2019).

Na Figura 3, vê-se as menções dos candidatos por redes televisivas entre 2015 e 2017. Novamente, Donald Trump encontra-se à frente dos demais candidatos, sendo os canais MSNBC, CNN e FOX News, nessa ordem, os que mais mencionaram Trump. No caso de Hillary, CNN, FOX News e MSNBC foram os canais que mais a mencionaram, também nessa ordem. Já as Figuras 4 e 5 mostram o porcentual de mençóes dos candidatos, separados por partidos. Nota-se que Clinton e Trump são os candidatos mais mencionados.

O maior número de mençôes a Trump, seguido de Hillary, pode ser explicado pelo tempo em que ambos ficaram em evidência na mídia, pois os dois foram os principais candidatos à presidência durante todo o período eleitoral, especialmente nos quatro últimos meses de campanha, a partir de julho - mês em que ambos foram nomeados candidatos oficiais pelos seus respectivos partidos - até o início de novembro, quando o dia eleitoral aconteceu. Já o número de menções por 
canais televisivos pode ser explicado apenas pelo teor político desses canais, que, por isso, fizeram uma cobertura mais assídua de cada momento das eleiçóes.

Além disso, as eleiçôes de 2016 foram bastante acaloradas e polarizadas, com um outsider, que não se abstinha de falar o que quisesse, como protagonista. A figura de Trump pode ter sido um fator para tantas mençôes nas redes. A relação de Trump com a mídia foi muito conturbada, e o uso constante de seu Twitter como maneira de se comunicar diretamente com o espectador pode ter alimentado as mençóes sobre si mesmo nos programas das redes televisivas (RAHAL, 2019).

Segundo Patterson (2016), um dos motivos para que Trump fosse táo mencionado pela mídia seria a sua vontade por exposição midiática.

Trump's dominant presence in the news stemmed from the fact that his words and actions were ideally suited to journalists' story needs. The news is not about what's ordinary or expected. It's about what's new and different, better yet when laced with conflict and outrage. Trump delivered that type of material by the cart load. Both nominees tweeted heavily during the campaign but journalists monitored his tweets more closely. ${ }^{27}$ (PATTERSON, 2016, p. 7).

No que tange o tom das mençóes à Trump - em específico -, Patterson (2016) apresenta uma pesquisa a respeito da abordagem negativa que foi dada à Trump (e à Clinton) durante as eleições de 2016 nos jornais escritos The Los Angeles Times, The New York Times, The Wall Street Journal, The Washington Post, e USA Today e nas redes televisivas ABC World News Tonight, CBS Evening News, CNN's The Situation Room, Fox's Special Report e NBC Nightly News. Segundo o autor, ambos os candidatos foram abordados mais negativamente que positivamente pela mídia, conforme exposto na Figura 6 - Tom da Cobertura dos Candidatos:

\footnotetext{
${ }^{27}$ Tradução nossa: A presença dominante de Trump na mídia originou-se do fato de que suas palavras e açóes foram idealmente adequadas para as necessidades por histórias dos jornalistas. As notícias não são sobre o que é comum ou esperado. É sobre o que é novo e diferente, melhor ainda quando relacionado com conflito e ofensas. Trump entregou esse tipo de material em abundância. Ambos os candidatos escreveram tweets durante a campanha, mas os jornalistas monitoraram os tweets de Trump com mais afinco.
} 
Figura 6 - Tom da Cobertura dos Candidatos ${ }^{28}$

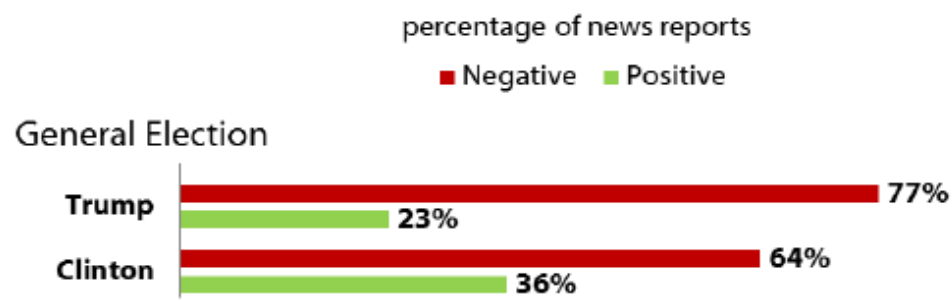

Full Campaign

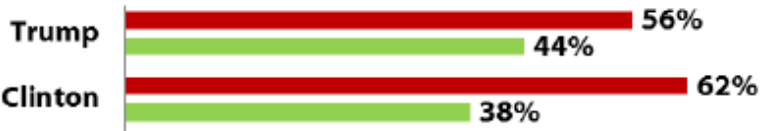

Fonte: Patterson (2016).

Entre os tópicos mais abordados pela mídia - todos com alta negatividade em tom -, horse race (abordagem com foco em pesquisas eleitorais e percepção pública) obteve $42 \%$ de foco, seguido de outras questôes - eventos seguintes, staff, logística, e outros - com 24\%, e controversas, com 17\%. Segundo Patterson (2016),

[...] to journalists, the real issues of presidential politics are not the candidates' policy commitments but instead the controversies that ensnare them. The 2016 campaign fit the pattern to a tee. Everything from Clinton's emails to Trump's taxes was grist for the media mill. They accounted for 17 percent of the coverage-one in every six news reports $^{29}$ (PATTERSON, 2016, p. 9).

Quanto à abordagem específica sobre Trump, sua cobertura foi majoritariamente feita com tom negativo. $\mathrm{O}$ canal $F O X$ foi o que proveu uma cobertura mais positiva. Isso é visível na Figura 7 - Tom da Cobertura de Trump

${ }^{28} \mathrm{O}$ período de Full campaign (toda a campanha) cobre o período de $1^{\circ}$ de janeiro de 2015 a 7 de novembro de 2016. O período de general election (eleiçóes gerais) cobrem o período de 8 de agosto a 7 de novembro de 2016.

29 Tradução nossa: para os jornalistas, as verdadeiras questões da política presidencialista não são os compromissos políticos dos candidatos, mas as controvérsias que os envolvem. A campanha de 2016 é o padrão. Tudo, desde os e-mails de Clinton até os impostos de Trump, era bom para a mídia. Eles representaram $17 \%$ da cobertura - um em cada seis reportagens. 
104 | Andressa Mendes e Filipe Mendonça

pelas Agências de Notícias. Suas opiniōes políticas garantiram muita cobertura jornalística, mesmo que fossem similares às de outros candidatos. O que o difere dos demais é o modo de se pronunciar. Por exemplo: no caso dos imigrantes não documentados, "Trump's words made it newsworthy. Immigrants were 'rapists,' 'murderers,' 'terrorists 30 " (PATTERSON, 2016, p. 16).

Figura 7 - Tom da Cobertura de Trump pelas Agências de Notícias

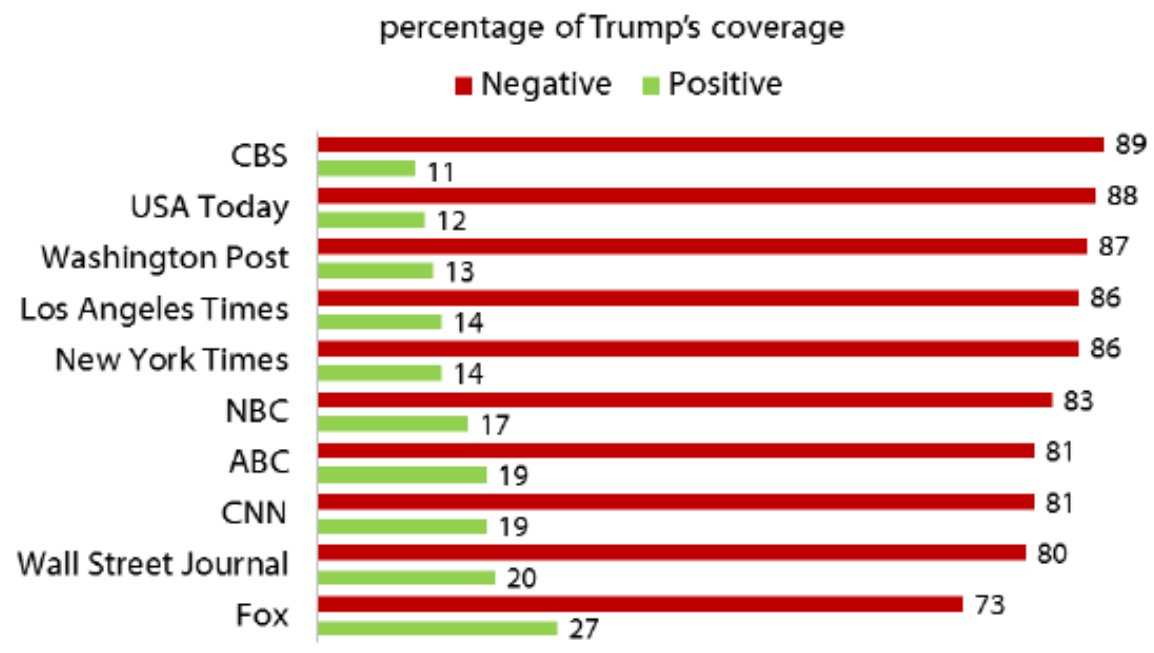

Fonte: Patterson (2016).

\section{Considerações finais a título de conclusão}

Em uma tentativa de entender se o Twitter de Donald Trump foi um instrumento de criação da agenda da grande imprensa durante as eleições presidenciais dos Estados Unidos de 2016, o artigo buscou apresentar variáveis para a compreensão teórica e prática do tema. A hipótese inicial era de que o Twitter de Trump auxiliou na construção da agenda da mídia tradicional durante o período em questão. Isso teria acontecido devido ao número de menções que Trump teve em redes televisivas estadunidenses, as quais foram feitas com base no volume de material fornecido por Trump pelo seu Twitter e pelo modo como ele se expressa publicamente.

30 Tradução nossa: as palavras de Trump fizeram-se notadas. Imigrantes eram 'estupradores', 'assassinos' e 'terroristas'. 
Conforme apresentado, entende-se que a hipótese inicial se comprova. Trump foi o candidato mais mencionado pelas redes televisivas durante todo o período eleitoral e entre os assuntos mais abordados pela mídia, pois relacionadas a ele encontram-se questóes controversas. Essas questôes envolvem polêmicas desenvolvidas durante as eleições, que muitas vezes aconteciam no Twitter, como os tweets de ataque à Hillary. $\mathrm{O}$ Twitter foi usado como canal oficial de comunicação de Trump, que designava à mídia tradicional o papel de disseminadora de notícias falsas. Como tentativa de desmentir o que era falado por Trump em seu Twitter, a mídia mencionava-o mais, de modo que o Twitter de Trump ajudou na construçáo da agenda midiática.

Tem-se, então, que a opinião pública e democracia são influenciadas por toda essa relação e dinâmica. A mídia, tradicional e nova, molda a opinião pública, fomenta debates e, indiretamente, polarizaçôes. Sua liberdade é garantida pela democracia, a qual, por sua vez, é ameaçada pela mídia devido a esses conflitos desencadeados pela agenda midiática. A figura de Trump, por si só e associada à mídia, é, segundo Levitsky e Ziblatt (2018), uma ameaça à democracia dos Estados Unidos, uma vez que ele se enquadra nos critérios dos autores.

Por fim, como já mencionado, este artigo tem caráter exploratório de um tema pouco explorado no Brasil. Não obstante, ele aponta para uma agenda importante de pesquisa para entender a política contemporânea: Como mensurar esta relação entre redes sociais e criação de agenda? Qual é o impacto do Twitter no debate político contemporâneo e para a polarização política? Quais são as metodologias interdisciplinares disponíveis para este tipo de pesquisa? Essas são apenas algumas das inúmeras questôes possíveis neste debate, cada vez mais crucial para a compreensão das democracias contemporâneas.

Andressa Gabrielly de Lacerda Mendes é Mestranda em Relações Internacionais pelo Programa de Pós-graduação em Relações Internacionais na Universidade Federal de Uberlândia (UFU). E-mail: glm.andressa@gmail.com.

Filipe Almeida do Prado Mendonça é Doutor em Ciência Politica pela Universidade de Campinas (UNICAMP). Professor do Programa de Pós-Graduação em Relações Internacionais da Universidade Federal de Uberlândia (UFU). E-mail: mendonca@ufu.br. 


\section{Referências}

ARTHUR, Charles. How Twitter was born: the first 140 users. The Guardian, 11 jan. 2010. Disponível em: <https://www.theguardian.com/technology/blog/2010/jan/11/Twitter-first-140users-history>. Acesso em: 02 ago. 2019.

BROWN, Brendan. Trump Twitter Archive. 2017. Disponível em: <http://www.trumpTwitterarchive.com/about>. Acesso em: 02 ago. 2019.

BRUNS, Axel. Gatewatching. New York: Peter Lang, 2005.

BRUNS, Axel; HIGHFIELD, Tim. May the best tweeter win: The Twitter strategies of key campaign accounts in the 2012 US election. In: BIEBER, Christoph; KAMPS, Klaus (Eds.). Die USPräsidentschaftswahl 2012. Wiesbaden: Springer, 2016. p. 425-442.

CASTELLS, Manuel. A galáxia da internet. Rio de Janeiro: Jorge Zahar, 2003.

CASTELLS, Manuel. A Sociedade em Rede. São Paulo: Paz e Terra, 1992.

CHUCK, Elizabeth. Fidel Castro Is Dead!' Trump Tweets, Attacks Legacy as a 'Brutal Dictator: 2016. NBC News, 26 nov. 2016. Disponível em: <https://www.nbcnews.com/storyline/fidelcastros-death/fidel-castro-dead-trump-tweets-attacks-legacy-brutal-dictator-n688591>. Acesso em: 03 set. 2019.

CONWAY-SILVA, Bethany A. et al. Reassessing Twitter's agenda-building power. Social Science Computer Review, v. 36, n. 4, p. 469-483, 4 jul. 2017.

DELREAL, Jose A. Donald Trump announces presidential bid. Washington Post, 16 jun. 2015. Disponível em: <https://www.washingtonpost.com/news/post-politics/wp/2015/06/16/donaldtrump-to-announce-his-presidential-plans-today/>. Acesso em: 03 ago. 2019.

DRUBSCKY, Luiza. Entenda o que é hashtag (\#) para que elas servem e como utilizá-las. 15 mar. 2018. Blog. Disponível em: <https://rockcontent.com/blog/o-que-e-hashtag/>. Acesso em: 02 ago. 2019.

ENLI, Gunn. Twitter as arena for the authentic outsider: exploring the social media campaigns of Trump and Clinton in the 2016 US presidential election. European Journal Of Communication, v. 32, n. 1, p. 50-61, fev. 2017.

ENLI, Gunn; NAPER, Anja Aaheim. Social media incumbent advantage: Barack Obama's and Mitt Romney's Tweets in the 2012 U.S. Presidential Election Campaign. In: BRUNS, Axel; ENLI, Gunn; SKOGERBØ, Eli (Eds.). The Routledge Companion to Social Media and Politics. New York: Routledge, 2016. p. 364-377.

FIDEL Castro, Cuba's leader of revolution, dies at 90. BBC News, 26 nov. 2016. Disponível em: <https://www.bbc.com/news/world-latin-america-38114953>. Acesso em: 03 ago. 2019.

GDELT PROJECT. Presidential Campaign 2016: Candidate Television Tracker. 2019. Disponível em: $<$ http://television.gdeltproject.org/cgibin/iatv_campaign2016/iatv_campaign2016?filter_candidate=\&filter_network=NATIONAL\&filter _timespan=SINCETRUMP\&filter_displayas=RAW>. Acesso em: 03 ago. 2019.

HABERMAS, Jürgen. Mudança estrutural na esfera pública: investigações quanto a uma categoria da sociedade burguesa. 2. ed. Rio de Janeiro: Tempo Brasileiro, 2003.

IANDOLI, Rafael. O que são os emails que ameaçam a campanha de Hillary Clinton. Nexo, 31 out. 2016. Disponível em: <https://www.nexojornal.com.br/expresso/2016/10/31/O-que-s\%C3\%A3oos-emails-que-amea\%C3\%A7am-a-campanha-de-Hillary-Clinton>. Acesso em: 03 ago. 2019. 
JUNGHERR, Andreas. Analyzing Political Communication with Digital Trace Data: The Role of Twitter Messages in Social Science Research. [S.l.]: Springer International Publishing, 2015.

KIMBALL, Spencer. Entenda como funcionam as primárias nos EUA. DW, 26 jan. 2016. Disponível em: <https://www.dw.com/pt-br/entenda-como-funcionam-as-prim\%C3\%A1 rias-nos-eua/a18994751>. Acesso em: 03 ago. 2019.

KREISS, Daniel. Seizing the moment: The presidential campaigns' use of Twitter during the 2012 electoral cycle. New Media and Society, v. 18, n. 8, p. 1473-1490, 2014.

LEDFORD, Christy J. W. Changing channels: a theory-based guide to selecting traditional, new, and social media in strategic social marketing. Social Marketing Quarterly, v. 18, n. 3, p. 175-186, 28 set. 2012.

LEE, Jayeon; XU, Weiai. The more attacks, the more retweets: Trump's and Clinton's agenda setting on Twitter. Public Relations Review, v. 44, n. 2, p. 201-213, jun. 2018.

LEVITSKY, Steven; ZIBLATT, Daniel. Como as democracias morrem. [S.l.]: Zahar, 2018.

MAGNOTTA, Fernanda; GRINBERG, Victor. Trump: mídia, opiniāo pública e a espiral do silêncio. Esboços: histórias em contextos globais, v. 24, n. 38, p. 396-409, 4 out. 2018.

MÁRQUEZ-DOMÍNGUEZ, Carmelo; LÓPEZ-LÓPEZ, Paulo Carlos; ARIAS, Tatiana Estévez. Social networking and political agenda: Donald trump's Twitter accounts. In: CISTI - Iberian Conference on Information Systems and Technologies, 12., [S.1.]: IEEE, jun. 2017. p. 1-6.

MAZA, Carlos. Why obvious lies make great propaganda: The propaganda trick Trump and Putin both use. Vox, 31 ago. 2018. Disponível em: <https:/www.vox.com/2018/8/31/17804104/strikethrough-lies-propaganda-trump-putin>. Acesso em: 10 nov. 2018.

McCARTHY, Ciara; PHIPPS, Claire. Election results timeline: how the night unfolded. The Guardian, 2016. Disponível em: <https:/www.theguardian.com/us-news/2016/nov/08/presidentialelection-updates-trump-clinton-news>. Acesso em: 03 ago. 2019.

McCOMBS, Maxwell. Setting the Agenda: Mass Media and Public Opinion. [S.1.]: John Wiley \& Sons, 2018.

MELANIA Trump plagiarism row: Staffer admits role in speech. BBC News, 20 jul. 2016. Disponível em: <https://www.bbc.com/news/world-us-canada-36850215>. Acesso em: 03 ago. 2019.

NYE, Joseph. The Paradox of American Power: Why the World' Only Superpower Can't Go It Alone. New York: Oxford University Press, 2002.

PARISER, Eli. The Filter Bubble. New York: The Penguin Press, 2011.

PATTERSON, Thomas E. News Coverage of the 2016 General Election: How the Press Failed the Voters. Shorenstein Center on Media, Politics and Public Policy, 2016. Disponível em: <https://shorensteincenter.org/news-coverage-2016-general-election/>. Acesso em: 03 ago. 2019.

PRESIDENTIAL Election Results: Donald J. Trump Wins. The New York Times, 09 ago. 2017. Disponível em: <https://www.nytimes.com/elections/2016/results/president>. Acesso em: 04 jul. 2019.

RAHAL, Sarah. Trump: Tweeting is 'my only form of defense' against media. The Detroit News, 30 jul. 2019. Disponível em: <https:/www.detroitnews.com/story/news/politics/2019/07/30/trumptweeting-my-only-form-defense-against-media/1874143001/>. Acesso em: 03 ago. 2019. 
ROBINSON, Eugene. Fidel Castro is dead, but Donald Trump could give Cuba's dictatorship new life. The Washington Post, 28 nov. 2016. Disponível em: $<$ https://www.washingtonpost.com/opinions/fidel-castro-is-dead-but-donald-trump-could-givecubas-dictatorship-new-life/2016/11/28/9ee6be00-b5a5-11e6-b8df600bd9d38a02_story.html?noredirect=on>. Acesso em: 03 set. 2019.

SCOTT, Eugene. Donald Trump: Fidel Castro is dead! CNN, 26 nov. 2016. Disponível em: $<$ https://edition.cnn.com/2016/11/26/politics/trump-reacts-to-castro-death/index.html>. Acesso em: 03 set. 2019.

TROTTIER, Daniel; FUCHS, Christian. Social Media, Politics and the State: Protests, Revolutions, Riots, Crime and Policing in the Age of Facebook, Twitter and YouTube. [S.1.]: Routledge Research in Information Technology and Society, 2014.

TRUMP, Donald J. It all begins today! I will see you at 11:00 A.M. for the swearing-in. THE MOVEMENT CONTINUES - THE WORK BEGINS! Washington D.C., 20 jan. 2017. Twitter: @realDonaldTrump. <https://Twitter.com/realdonaldtrump/status/822421390125043713>. Acesso em: 12 dez. 2019.

TRUMP, Donald J. How long did it take your staff of 823 people to think that up--and where are your 33,000 emails that you deleted? Washington D.C., 9 jun. 2016a. Twitter: @realDonaldTrump. Disponível em: <https://Twitter.com/realDonaldTrump/status/741007091947556864>. Acesso em: 12 dez. 2019.

TRUMP, Donald J. The media is spending more time doing a forensic analysis of Melania's speech than the FBI spent on Hillary's emails. Washington D.C., 20 jul. 2016b. Twitter: @realDonaldTrump.

Disponível

em: <https://Twitter.com/realDonaldTrump/status/755788382618390529>. Acesso em: 12 dez. 2019.

TRUMP, Donald J. TODAY WE MAKE AMERICA GREAT AGAIN! Washington D.C., 8 nov. 2016c. Twitter: @realDonaldTrump. Disponível em: <https://Twitter.com/realDonaldTrump/status/795954831718498305>. Acesso em: 12 dez. 2019.

TRUMP, Donald J. Such a beautiful and important evening! The forgotten man and woman will never be forgotten again. We will all come together as never before. Washington D.C., 9 nov. 2016d. Twitter: @realDonaldTrump. Disponível em: <https://Twitter.com/realDonaldTrump/status/796315640307060738>. Acesso em: 12 dez. 2019.

TRUMP, Donald J. Fidel Castro is dead! Washington D.C., 26 nov. 2016e. Twitter: @realDonaldTrump. Disponível em: <https://Twitter.com/realDonaldTrump/status/802499192237080576>. Acesso em: 12 dez. 2019.

TRUMP PENCE. [Homepage]. 2019. Disponível em: <https://www.donaldjtrump.com/>. Acesso em: 02 ago. 2019.

TWITTER aumenta limite para 280 caracteres. G1, 07 nov. 2017. Disponível em: <https://g1.globo.com/tecnologia/noticia/Twitter-aumenta-limite-para-280-caracteres.ghtml>. Acesso em: 03 ago. 2019.

US POLITICAL Parties: (Party Registration Numbers Current as of Apr. 2014). Procon, 08 set. 2016. Disponível em: <https://2016election.procon.org/view.resource.php?resourceID=005928>. Acesso em: 03 ago. 2019. 
VAN AELST, Peter et al. Political communication in a high-choice media environment: a challenge for democracy? Annals Of The International Communication Association, [S.1.], v. 41, n. 1, p. 3-27, 2 jan. 2017.

VIEIRA, Vivian Patricia Peron. Os Efeitos da Comunicação Digital na Dinâmica do Ativismo Transnacional Contemporâneo: um estudo sobre Al-Qaeda, Wikleaks e Primavera Árabe. 2016. 381 f. Tese (Doutorado em Relações Internacionais) - Programa de Pós-Graduação em Relaçóes Internacionais, Universidade de Brasília, Brasília, 2016. Disponível em: <http://repositorio.unb.br/bitstream/10482/20904/1/2016_VivianPatriciaPeronVieira.pdf>. Acesso em: 08 nov. 2019.

Texto recebido em 05 de setembro de 2019. Aprovado em 26 de novembro de 2019. 